Revista Brasileira de Geografia Física, vol. 7, n. 4 (2014) 642-652.

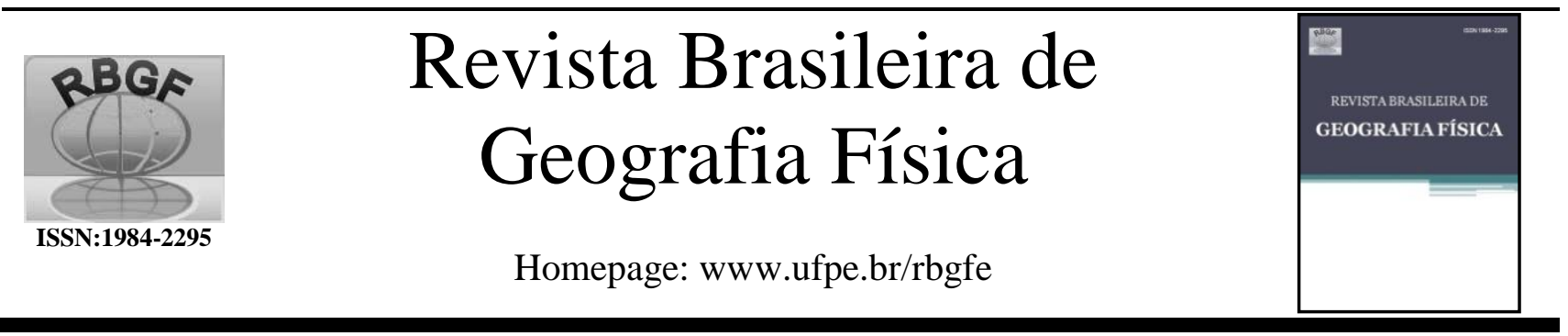

\title{
Qualidade da Água e Vulnerabilidade dos Recursos Hídricos Superficiais na Definição das Fragilidades Potencial e Ambiental de Bacias Hidrográficas
}

Thiara Silveira ${ }^{1}$, Neylor Alves Calasans Rego ${ }^{2}$, José Wildes Barbosa dos Santos ${ }^{3}$, Maria do Socorro Bezerra de Araújo 4

\begin{abstract}
${ }^{1}$ Dissertação de Mestrado defendida no Curso de Mestrado em Meio Ambiente e Desenvolvimento Regional da Universidade Estadual de Santa Cruz - UESC. E-mail: thiara.silveira@bol.com.br

${ }^{2}$ Professor Pleno do Departamento de Ciências Agrárias e Ambientais da Universidade Estadual de Santa Cruz - UESC, Campus Soane Nazaré de Andrade, Rodovia Jorge Amado, Km 16, Bairro Salobrinho, CEP 45662-900. Ilhéus-Bahia. Email: neylorcalasans@gmail.com - Autor correspondente.

${ }^{3}$ Professor Adjunto do Departamento de Estudos Básicos e Instrumentais da Universidade Estadual do Sudoeste da Bahia UESB.

${ }^{4}$ Professora Adjunto IV da Universidade Federal de Pernambuco - UFPE. E-mail: socorro@ufpe.br
\end{abstract}

Artigo recebido em 09/04/2014 e aceito em 29/09/2014.

\begin{abstract}
R E S U M O
O conhecimento sobre as fragilidades potencial ambiental de uma bacia hidrográfica possibilita identificar e analisar os ambientes em seus diferentes níveis de organização, auxiliando nos trabalhos de zoneamento ambiental, gestão territorial e na compreensão da relação dinâmica entre os componentes naturais e os fatores antrópicos. Nesse sentido, o objetivo deste trabalho foi avaliar as fragilidades potencial e ambiental na bacia hidrográfica do rio Catolé Grande, sudoeste da Bahia, acrescentando-se parâmetros relativos à malha hídrica e qualidade da água à metodologia estabelecida na literatura. A fragilidade potencial foi definida com base em informações sobre a declividade, tipo de solo, pluviosidade, geologia, geomorfologia e malha hídrica. A fragilidade ambiental foi obtida através dos resultados da fragilidade potencial acrescido de dados sobre o uso do solo e qualidade da água através da utilização do Índice de Qualidade da Água, que foi determinado em amostras de água coletadas em oito pontos ao longo da malha hídrica da bacia. Todos os parâmetros foram integralizados utilizando-se ferramentas do software ArcGis 9.3, gerando os mapas sínteses das fragilidades potencial e ambiental. A inclusão do IQA influenciou a definição da fragilidade ambiental, aumentando as áreas com baixa fragilidade, provavelmente devido às condições boas e ótimas da água encontradas nos locais amostrados. O nível de vulnerabilidade dos recursos hídricos superficiais influenciou negativamente a fragilidade potencial e em menor escala a fragilidade ambiental. O trabalho mostrou a importância da inclusão de novos fatores ambientais para o estabelecimento das fragilidades potencial e ambiental de bacias hidrográficas proporcionando a obtenção de informações importantes para o um manejo integrado da área.
\end{abstract}

Palavras-chave: fragilidade potencial, fragilidade ambiental, pluviosidade, declividade, tipo de solo, qualidade da água, geomorfologia, geologia

\section{Water Quality and Surface Water Resources Vulnerability in the Definition of Potential and Environmental Fragilities of Watersheds}

\section{A B S T R A C T}

The knowledge about the potential and environmental fragilities of watersheds makes possible to identify and to analyze the environment, their different organization levels, being relevant in the environmental zoning, territorial administration and in the understanding of the dynamic relationship between the natural components and the anthropic factors. In that sense, the objective of this work was to develop the evaluation of the potential and environmental fragilities of the rio Catole Grande watershed located in the southwest of the Bahia state. The used methodology was the one proposed by Ross (1994), 


\section{Revista Brasileira de Geografia Física, vol. 7, n. 4 (2014) 642-652.}

modified by including environmental factors related to the quality of the superficial water resources and he hydric network. The potential fragility was defined based on information about slope, soil type, geology, geomorphology, rainfall and the hydric network. The environmental fragility was obtained through the results of the potential fragility, use of the soil and the Water Quality Index determined by the analysis of water samples collected in eight sampling points. All the parameters were integrated using the available tools of the software ArcGis 9.3, generating the syntheses maps of the potential and environmental fragilities. The inclusion of the IQA influenced the definition of the environmental fragility, increasing the areas with low fragility, probably due to the good and very good water conditions found in the sampled places. The vulnerability levels of the superficial water resources influenced negatively the potential fragility and in smaller scale the environmental fragility. The work showed the importance of including new environmental factors for the establishment of the potential and environmental fragilities of watersheds, providing important information for an integrated management of the area.

Keywords: environmental fragility, potential fragility, rainfall, slope, soil type, water quality, geology, geomorphology

Segundo Ross (1944), fragilidade potencial é a

Introdução

Os estudos sobre a fragilidade ambiental possibilitam identificar e analisar os sistemas ambientais em seus diferentes níveis de organização, auxiliando nos trabalhos de zoneamento ambiental, gestão territorial e na compreensão da dinâmica entre os componentes naturais e os fatores antrópicos aonde o tipo de uso e modificações na cobertura vegetal vêm resultando em influências no clima, na velocidade dos processos erosivos, na diversidade biológica e conseqüentemente no balanço hídrico, dentre outros.

O mapeamento da fragilidade do ambiente constitui-se numa importante ferramenta que auxilia no ordenamento adequado do meio ambiente, indicando áreas mais e menos favoráveis à sua ocupação permitindo avaliar as potencialidades do meio ambiente de forma integrada, compatibilizando suas características naturais com suas restrições (KAWAKUBO et al., 2005).

A metodologia para avaliação da fragilidade empírica proposta por Ross (2004) fundamenta-se no princípio de que a natureza apresenta funcionalidade intrínseca entre suas componentes e utilizam informações do relevo, solo, geologia, clima, uso da terra, cobertura vegetal, possibilitando a análise das fragilidades potencial e ambiental. vulnerabilidade natural do ambiente e a fragilidade ambiental, a vulnerabilidade natural associada aos graus de proteção que os diferentes tipos de uso e cobertura vegetal exercem.

O objetivo deste trabalho consiste em mapear a fragilidade ambiental e potencial da bacia hidrográfica do rio Catolé Grande (BA) através da inclusão de novos fatores ambientais com o objetivo de obter um maior detalhamento das fragilidades no mapa síntese.

\section{Material e Métodos}

\section{Área de Estudo}

A bacia hidrográfica do rio Catolé Grande (BHRCG), situada na região sudoeste da Bahia entre as coordenadas $40^{\circ} 50^{\prime} \mathrm{W}$ e $40^{\circ} 10^{\prime} \mathrm{W}$ de longitude e $14^{\circ} 40^{\prime}$ $\mathrm{S}$ e $15^{\circ} 20^{\prime} \mathrm{S}$ de latitude, compreende uma área de drenagem de aproximadamente $2.997,7 \mathrm{~km}^{2}$, pertencente à $\mathrm{BH}$ do rio Pardo. Seu território abrange partes de oito municípios, sendo eles: Vitória da Conquista; Itambé; Barra do Choça; Caatiba; Itapetinga; Nova Canaã; Planalto e uma pequena parte do município de Itarantim, local onde situa-se o exutório da bacia, conforme a Figura 1, compreendendo uma população de aproximadamente 545.000 habitantes (OLIVEIRA, 2007). 
Revista Brasileira de Geografia Física, vol. 7, n. 4 (2014) 642-652.

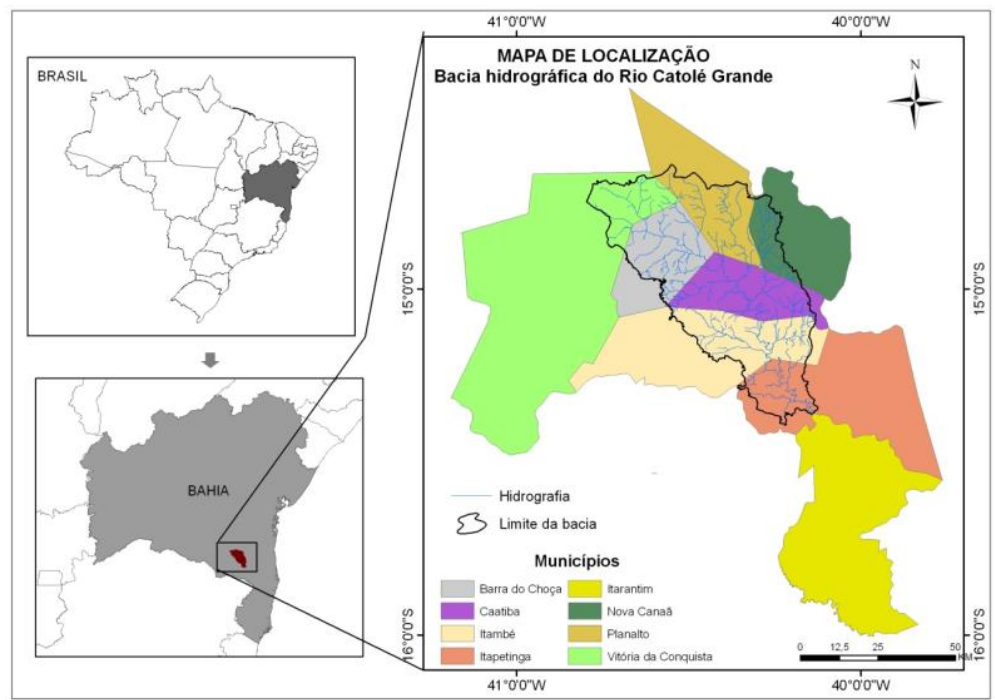

Figura 1- Localização da bacia hidrográfica do rio Catolé Grande, localizada no sudoeste da Bahia, circundada de preto, abrangendo parte de oito municípios.

\section{Fragilidade Potencial e Ambiental}

A avaliação da fragilidade potencial foi realizada utilizando-se informações referentes à declividade, solos, pluviosidade, geologia e a geomorfologia da área, acrescentadas de informações relativas à malha hídrica da bacia hidrográfica. A hierarquização para definição das classes de fragilidade foi desenvolvida através da sobreposição dos mapas temáticos e dos valores individuais obtidos para cada fator (Equação 1).

$$
F P=\frac{(D+S+P V+G E O+G E O M+M H)}{6}
$$

Em que:

(Equação 1)

$\mathrm{FP}=$ fragilidade potencial;

$\mathrm{D}=$ declividade;

$\mathrm{PV}=$ pluviosidade;

$\mathrm{GEO}=$ geologia;

GEOM = geomorfologia; $\mathrm{e}$

$\mathrm{MH}=$ malha hídrica.

A fragilidade ambiental foi desenvolvida através dos resultados obtidos para fragilidade potencial, sendo incorporados os parâmetros Uso da Terra e Índice de Qualidade de Águas (CETESB, 2004), conforme Equação 2.

$$
F A=\frac{(F P+U S+I Q A)}{3}(\text { Equação } 2)
$$

Em que:

$\mathrm{FA}=$ fragilidade potencial;

US = uso do solo; $\mathrm{e}$

IQA = índice de qualidade de água.
Os procedimentos utilizados possibilitaram gerar os mapas sínteses apresentando os diferentes graus das fragilidades da área em estudo. Os produtos cartográficos e cálculos foram realizados no software ArcGis Desktop 9.3.

\section{Pluviosidade}

A obtenção de dados pluviométricos da BHRCG foi realizada utilizando-se a base geográfica fornecida pela Companhia de Pesquisa de Recursos Minerais CPRM (2010). Os valores de precipitação para as áreas entre as isoietas foram obtidos através da utilização da ferramenta Geoestatística de Krigagem do software ArcGis 9.3.

A hierarquização foi realizada utilizando os dados da tabela 1 , adaptado às médias pluviométricas da BHRCG.

Tabela 1 - Níveis hierárquicos utilizados na avaliação de fragilidades potencial e ambiental da bacia hidrográfica do rio Catolé Grande, sudoeste da Bahia, adaptados para faixas de pluviosidade média anual ocorrentes na bacia.

\begin{tabular}{ccc}
\hline $\begin{array}{c}\text { Pluviosidade Média } \\
\text { Anual (mm) }\end{array}$ & Peso & Classificação \\
\hline 600 & 3 & Média \\
700 & 4 & Alta \\
800 & 5 & Muito Alta \\
\hline
\end{tabular}

Fonte: Modificado de Sporl (2001)

\section{Declividade}

A obtenção dos dados referentes à declividade da bacia hidrográfica foi realizada utilizando-se dados provenientes do projeto TOPODATA (2009), com resolução de $30 \mathrm{~m}$. A hierarquização dos níveis de fragilidade e atribuição dos pesos foi baseada na metodologia proposta por De Biasi (1992), onde, menores pesos se referem a áreas com menores 
Revista Brasileira de Geografia Física, vol. 7, n. 4 (2014) 642-652.

inclinações e maiores pesos, a terrenos com declividades mais elevadas (Tabela 2).

Tabela 2 - Níveis hierárquicos utilizados na avaliação de fragilidades potencial e ambiental da bacia hidrográfica do rio Catolé Grande, sudoeste da Bahia, para as classes de declividade ocorrentes na bacia.

\begin{tabular}{ccc}
\hline $\begin{array}{c}\text { Classes de } \\
\text { Declividade }(\%)\end{array}$ & Pesos & Classificação \\
\hline $0-5$ & 1 & Muito Baixa \\
$5-12$ & 2 & Baixa \\
$12-30$ & 3 & Média \\
$30-47$ & 4 & Alta \\
$>47$ & 5 & Muito Alta \\
\hline
\end{tabular}

Solos

Fonte: De Biasi, (1992)

As informações referentes aos diversos tipos de solos presentes na bacia foram obtidas no Mapa Pedológico do Estado da Bahia (CPRM, 2010) e a erodibilidade calculada através da metodologia de Wischmeier e Smith (1978). A hierarquização em relação à vulnerabilidade dos solos presentes na bacia é apresentada na tabela 3 .

Tabela 3 - Níveis hierárquicos utilizados na avaliação de fragilidades potencial e ambiental da bacia hidrográfica do rio Catolé Grande, sudoeste da Bahia para os tipos de solos ocorrentes na bacia.

\begin{tabular}{lcc}
\hline \multicolumn{1}{c}{ Solos } & Pesos & Classificação \\
\hline $\begin{array}{l}\text { Latossolo Vermelho- } \\
\text { Amarelo Distrófico }\end{array}$ & 2 & Baixa \\
$\begin{array}{l}\text { Argissolo Vermelho- } \\
\text { Amarelo Eutrófico }\end{array}$ & 3 & Média \\
\hline
\end{tabular}

\begin{tabular}{lll}
\hline Argissolo Vermelho- & 3 & Média \\
Amarelo Distrófico & & \\
\hline
\end{tabular}

Fonte: Modificado de Wischmeier e Smith (1978)

\section{Geomorfologia}

O mapa geomorfológico foi elaborado baseado na análise da imagem do projeto Topodata (2009), sendo delimitadas as diferentes classes geomorfológicas da bacia. A hierarquização dos níveis de fragilidade foi baseada na metodologia de Crepani et al., (2001), conforme mostrado na tabela 4 .

Tabela 4 - Níveis hierárquicos utilizados na avaliação de fragilidades potencial e ambiental da bacia hidrográfica do rio Catolé Grande, sudoeste da Bahia em relação à geomorfologia da bacia.

\begin{tabular}{lccc}
\hline \multicolumn{1}{c}{$\begin{array}{c}\text { Caracterização } \\
\text { Geomorfológica }\end{array}$} & Pesos & Classificação \\
\hline $\begin{array}{l}\text { Depressão Intramontanas } \\
\text { com Serras }\end{array}$ & 3 & Média \\
$\begin{array}{l}\text { Serras Marginais } \\
\text { Serras Marginais e }\end{array}$ & 5 & Muito Alta \\
$\begin{array}{l}\text { Escarpas } \\
\text { Pediplano Cimero da } \\
\text { Chapada Diamantina }\end{array}$ & 1 & Muito Baixa \\
\hline
\end{tabular}

Fonte: Adaptado de Crepani et al. (2001)

\section{Geologia}

A delimitação das unidades geológicas presentes na BHRCG foi baseada nas informações do projeto Topodata (2009). A hierarquização foi baseada na metodologia de Emmanouloudis (2003), conforme tabela 5 .

Tabela 5 - Níveis hierárquicos utilizados na avaliação de fragilidades potencial e ambiental da bacia hidrográfica do rio Catolé Grande, sudoeste da Bahia, em relação à geologia da bacia.

\begin{tabular}{llc}
\hline \multicolumn{1}{c}{ Unidade Geológica } & \multicolumn{1}{c}{ Litotipo } & Pesos \\
\hline Jequié - ortognaisses & Anatexito, Migmatito, Ortognaisse & 0.8 \\
\hline Barreiro Dantas e Jurema - Travessão & Anfibolito, Metabasalto, Metachert, Metapelito, \\
& Metatufo, Mármore, Rocha Metassedimentar & 1.1 \\
& Química & 0.5 \\
Jequié - charnockitos & Charnockito & 1 \\
Itabuna - tonalitos & Dacito, Riolito, Tonalito, Trondhjemito & 1.4 \\
Macaúbas, unidade de diamictitos & Diamictito & 1.8 \\
\hline Rio Gavião / Mirante & Folhelho, Grauvaca, Rocha Metavulcânica Félsica \\
Sete Voltas / Boa Vista / Mata Verde & Gnaisse & 0.7 \\
Itapetinga & Gnaisse, Migmatito, Ortognaisse & 0.7 \\
Gavião, migmatitos & Migmatito & 0.2 \\
Depósitos detrito-lateríticos & Sedimento Detrito-Laterítico & 1.8 \\
\hline
\end{tabular}

Fonte: Adaptado de Emmanouloudis et al., (2003)

\section{Malha Hídrica}

A incorporação na metodologia de aspectos referentes à malha hídrica da bacia permite o 


\section{Revista Brasileira de Geografia Física, vol. 7, n. 4 (2014) 642-652.}

delineamento de áreas tampão dos corpos hídricos, visando minimizar o impacto de cargas poluentes.

No presente trabalho, a vulnerabilidade hidrológica significa a maior ou menor susceptibilidade de um recurso hídrico ser afetado por uma carga poluente imposta, dependendo somente de características do meio físico, independentemente da existência de cargas poluidoras.

A identificação de áreas hidrologicamente vulneráveis à poluição é de grande importância para mitigação de riscos, desenvolvimento de políticas públicas, planos de manejo e programas educacionais que visem a proteção dos recursos hídricos de uma bacia hidrográfica.

A metodologia utilizada foi a de Harum et. al., (2008) que define zonas de exposição da área estudada ao longo dos rios sendo que a menor distância do centro dos rios está associada a uma maior vulnerabilidade.

O procedimento utilizado incluiu a divisão de toda a malha hídrica da bacia hidrográfica em dois grupos: o primeiro incluindo os rios principais e o segundo compreendendo os outros rios restantes. Utilizando-se a função Buffer do software ArcGis Desktop 9.3, foram definidas as zonas de exposição ao longo dos rios. Os níveis hierárquicos referentes à malha hídrica são apresentados na tabela 6 .

Tabela 6 - Níveis hierárquicos utilizados na avaliação de fragilidades potencial e ambiental da bacia hidrográfica do rio Catolé Grande, sudoeste da Bahia, em relação à distância do centro dos rios principais e secundários e suas zonas de exposição.

\begin{tabular}{cccc}
\hline Rios & $\begin{array}{c}\text { Distância do } \\
\text { Centro }(\mathbf{m})\end{array}$ & Peso & Classificação \\
\hline \multirow{3}{*}{ Grupo 1 } & 200 & 3 & Media \\
& 400 & 2 & $\begin{array}{c}\text { Baixa } \\
\text { Muito Baixa } \\
\end{array}$ \\
& 800 & 1 & \\
Grupo 2 & 100 & 3 & Media \\
& 200 & 2 & Baixa \\
& 300 & 1 & Muito Baixa \\
\hline
\end{tabular}

Fonte: Adaptado de Harum et al., (2008). Grupo 1 - rios principais; Grupo 2 - rios secundários.

\section{Uso da Terra e Cobertura Vegetal}

Para a definição dos tipos de uso da terra foram utilizadas imagens de satélite LANDSAT 5, onde foi feita uma classificação supervisionada com o intuito de reconhecer e separar os tipos representativos de uso da terra presentes. A hierarquização foi feita baseada em Kawakubo (2005) e apresentada na tabela 7.
Tabela 7 - Níveis hierárquicos utilizados na avaliação da fragilidade ambiental da bacia hidrográfica do rio Catolé Grande, sudoeste da Bahia, referentes a uso da terra e cobertura vegetal da BHRCG.

\begin{tabular}{ccc}
\hline $\begin{array}{c}\text { Classes de uso } \\
\text { da terra }\end{array}$ & Pesos & Classificação \\
\hline Área Urbana & 4 & Alta \\
Pastagem & 3 & Media \\
Eucalipto & 3 & Media \\
Mata & 1 & Muito Baixa \\
Mata secundaria & 2 & Baixa \\
Solo Exposto & 5 & Muito Alta \\
\hline
\end{tabular}

Fonte: Adaptado de Kawakubo et al., (2005)

\section{Índice de Qualidade de Água (IQA)}

O Índice de Qualidade de Água (CETESB, 2004) foi incorporado na avaliação da fragilidade ambiental objetivando avaliar aspectos referentes a qualidade de água da bacia e sua influência no mapa síntese da fragilidade ambiental.

A determinação do IQA foi obtida pelo produtório ponderado correspondente a nove parâmetros analisados nas amostras de água: oxigênio dissolvido (OD), demanda bioquímica de oxigênio (DBO), coliformes fecais, temperatura, $\mathrm{pH}$, nitrogênio total, fosfato total, turbidez e resíduo total, conforme Equação 3.

$$
I Q A=\prod_{1}^{n} q_{i}^{w_{t}} \quad \text { (Equação 3) }
$$

Em que:

IQA = índice de qualidade da água (de 0 a 100);

qi = qualidade da i-ésima variável, obtida através do respectivo gráfico de qualidade, em função do resultado da análise de água; e

wt $=$ peso correspondente à i-ésima variável fixado em função de sua importância para a conformação da qualidade da água.

Foram selecionados oito pontos amostrais de coleta de água ao longo de toda malha hídrica da bacia de modo que se obtivesse a máxima cobertura geográfica (Figura 2) e realizadas cinco campanhas amostrais (junho a dezembro de 2011). As análises químicas dos parâmetros do IQA foram executadas de acordo com as recomendações do APHA (1995) no Laboratório de Água da Universidade Estadual de Santa Cruz (UESC). 
Revista Brasileira de Geografia Física, vol. 7, n. 4 (2014) 642-652.

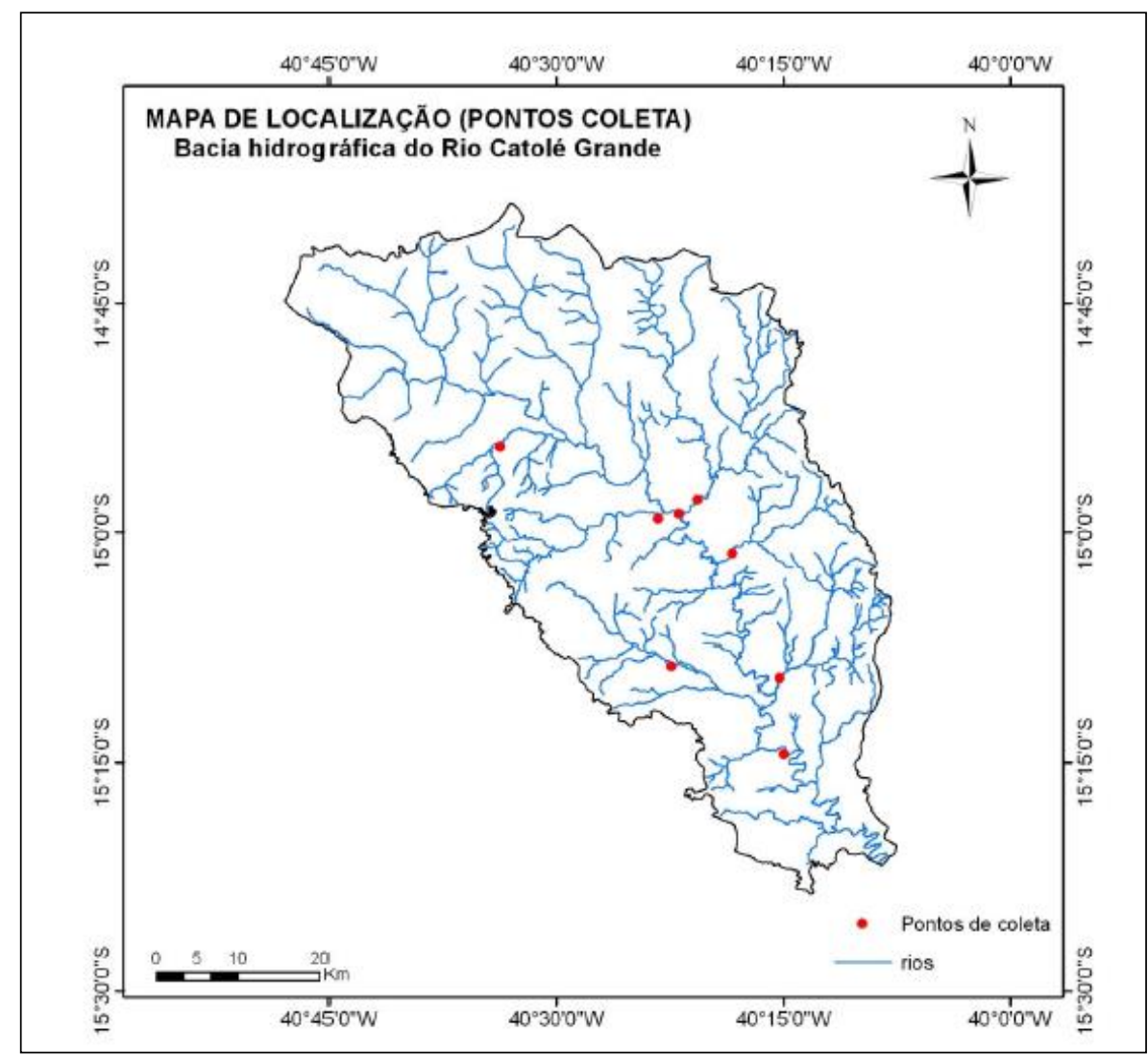

Figura 2 - Localização das áreas de coleta de amostras de água na bacia hidrográfica da bacia do rio Catolé Grande, sudoeste da Bahia, representada por pontos vermelhos.

A hierarquização dos valores obtidos para o IQA na classificação sugerida pela CETESB (2004) é apresentada na tabela 8.

Tabela 8 - Níveis hierárquicos utilizados na avaliação da fragilidade ambiental da bacia hidrográfica do rio Catolé Grande, sudoeste da Bahia, referentes ao Índice de Qualidade de Água, determinado para a bacia.

\begin{tabular}{cccc}
\hline Categoria & Ponderação & Pesos & Classificação \\
\hline Ótima & $79<\mathrm{IQA} \leq 100$ & 1 & Muito Baixa \\
Boa & $51<\mathrm{IQA} \leq 79$ & 2 & Baixa \\
Regular & $36<\mathrm{IQA} \leq 51$ & 3 & Média \\
Ruim & $19<\mathrm{IQA} \leq 36$ & 4 & Alta \\
Péssima & $\mathrm{IQA} \leq 19$ & 5 & Muito Alta \\
\hline
\end{tabular}

Fonte: Modificado de CETESB (2004)

\section{Resultados e Discussão}

\section{Fragilidade Potencial}

As diferentes classes de fragilidade ambiental da bacia foram mapeadas (Figura 3), tomando-se como base o tamanho da área de cada classe (Tabela 9). De forma geral, a bacia apresentou um nível médio de fragilidade. 
Revista Brasileira de Geografia Física, vol. 7, n. 4 (2014) 642-652.

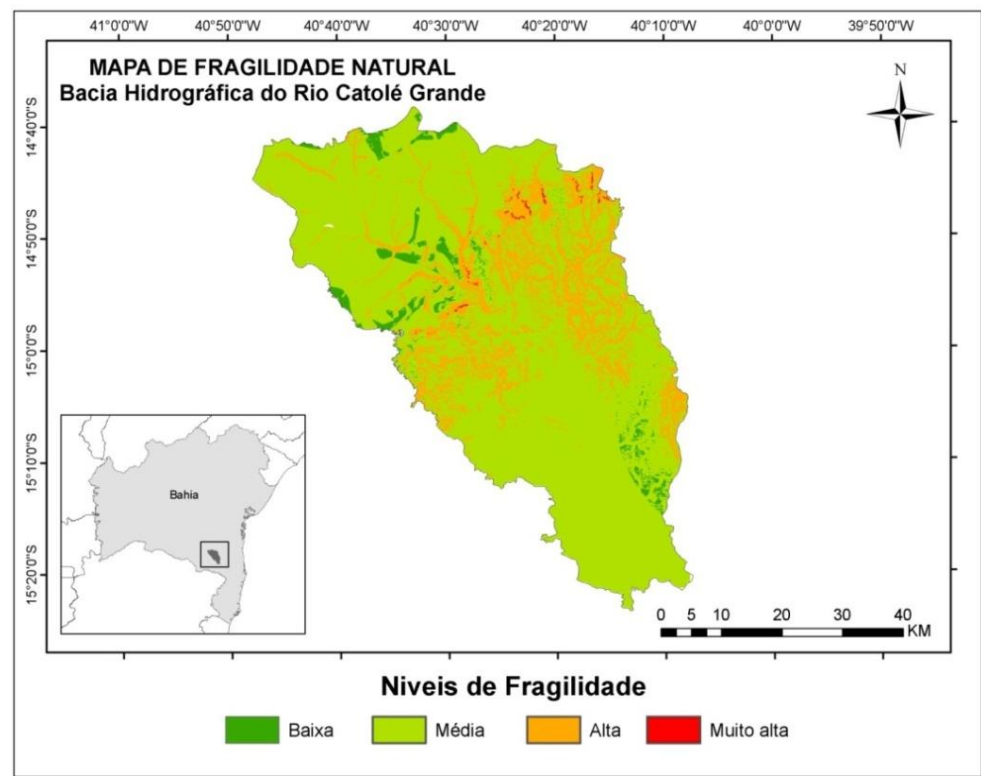

Figura 3 - Distribuição espacial dos níveis de fragilidade potencial na bacia hidrográfica do rio Catolé Grande, localizada no sudoeste da Bahia.

Tabela 9 - Área da bacia hidrográfica do rio Catolé Grande, sudoeste da Bahia, correspondente a cada nível de fragilidade potencial.

\begin{tabular}{ccc}
\hline Níveis de Fragilidade Potencial & Área $\left(\mathbf{K m}^{2}\right)$ & Área $\mathbf{( \% )}$ \\
\hline Baixa & 91,60 & 3,04 \\
Média & 2400,55 & 80,08 \\
Alta & 500,10 & 16,68 \\
Muito alta & 5,45 & 0,20 \\
Total & 2997,70 & 100,00 \\
\hline
\end{tabular}

As fragilidades potenciais altas e muito altas foram observadas ao longo da malha hídrica, principalmente no médio curso da bacia, indicando alta susceptibilidade dos recursos hídricos a cargas poluentes. Isto mostra a importância da inclusão de análises de qualidade relacionadas aos recursos hídricos na avaliação da fragilidade potencial, possibilitando uma avaliação mais detalhada da área.

As elevadas declividades apresentadas no médio curso da bacia mostradas na Figura 4 também contribuíram para a definição das áreas com fragilidade alta. 
Revista Brasileira de Geografia Física, vol. 7, n. 4 (2014) 642-652.

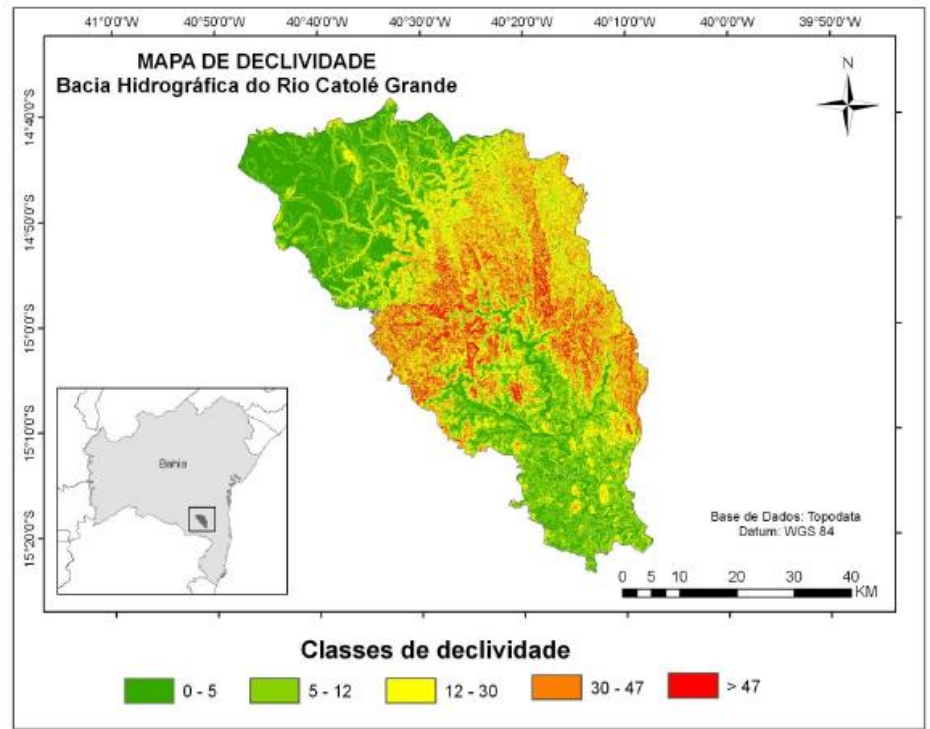

Figura 4 - Classes de declividade da bacia hidrográfica do rio Catolé Grande, localizada no sudoeste da Bahia.

As áreas consideradas como de baixa fragilidade potencial ocuparam pequena percentagem da área total da bacia e correspondem a áreas de menor declividade e solos mais profundos e com boa capacidade de drenagem (Latossolo Vermelho-Amarelo distrófico).

$\mathrm{O}$ fato de a bacia ser classificada em sua maior parte como de média fragilidade, sugestiona a importância de serem tomadas medidas preventivas nos planejamentos ambientais e de uso da terra, visando a manutenção do equilíbrio dinâmico nessas áreas, de maneira que a qualidade ambiental não venha a ser deteriorada.

\section{Fragilidade Ambiental}

As diferentes classes de fragilidade ambiental da bacia foram distribuídas espacialmente conforme apresentado na figura 5 e Tabela 10. Similarmente à fragilidade potencial, a maior parte da bacia se encontra no nível médio de fragilidade ambiental.

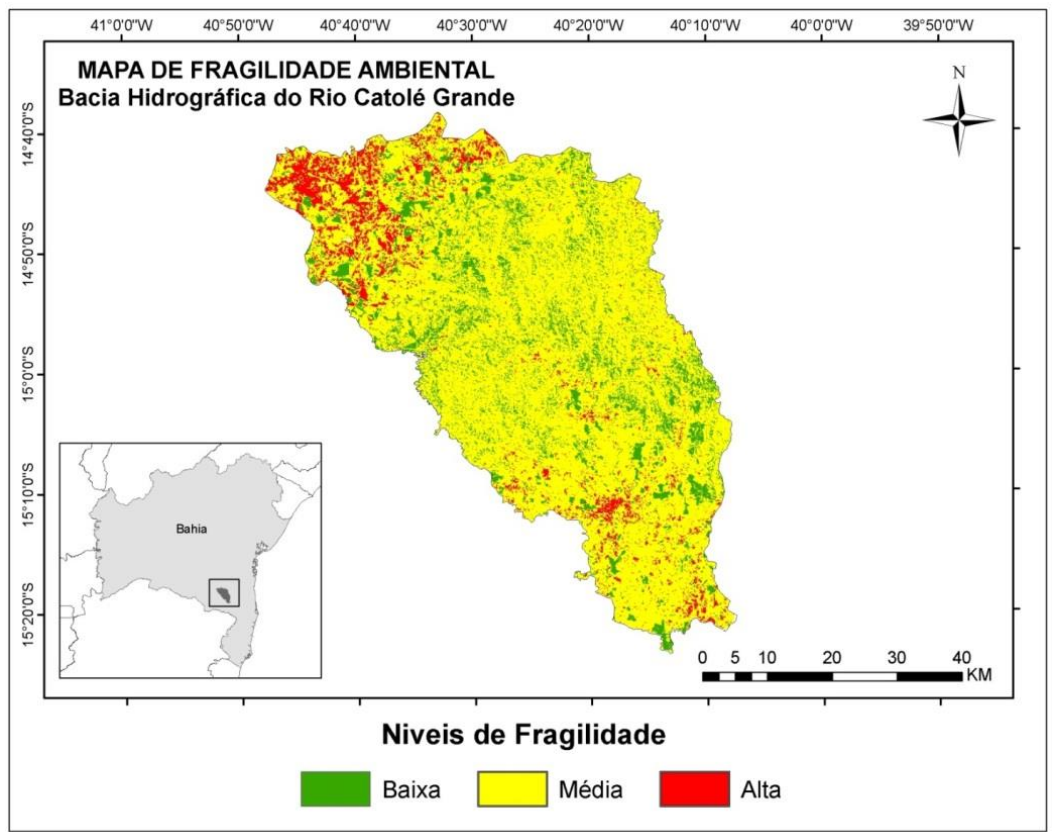

Figura 5 - Distribuição espacial dos níveis de fragilidade ambiental da bacia hidrográfica da bacia do rio Catolé Grande. 
Revista Brasileira de Geografia Física, vol. 7, n. 4 (2014) 642-652.

Tabela 10- Área da bacia hidrográfica do rio Catolé Grande, sudoeste da Bahia, correspondente a cada nível de fragilidade ambiental

\begin{tabular}{ccc}
\hline Níveis de Fragilidade Ambiental & Área $\left(\mathbf{K m}^{2}\right)$ & Área $(\%)$ \\
\hline Baixa & 421,33 & 14,10 \\
Média & 2335,50 & 77,90 \\
Alta & 240,87 & 8,00 \\
Total & 2997,70 & 100,00 \\
\hline
\end{tabular}

As áreas com fragilidade ambiental alta foram predominantemente definidas na porção norte

solo exposto (Figura 6), acentuada pela vulnerabilidade referente aos recursos hídricos.

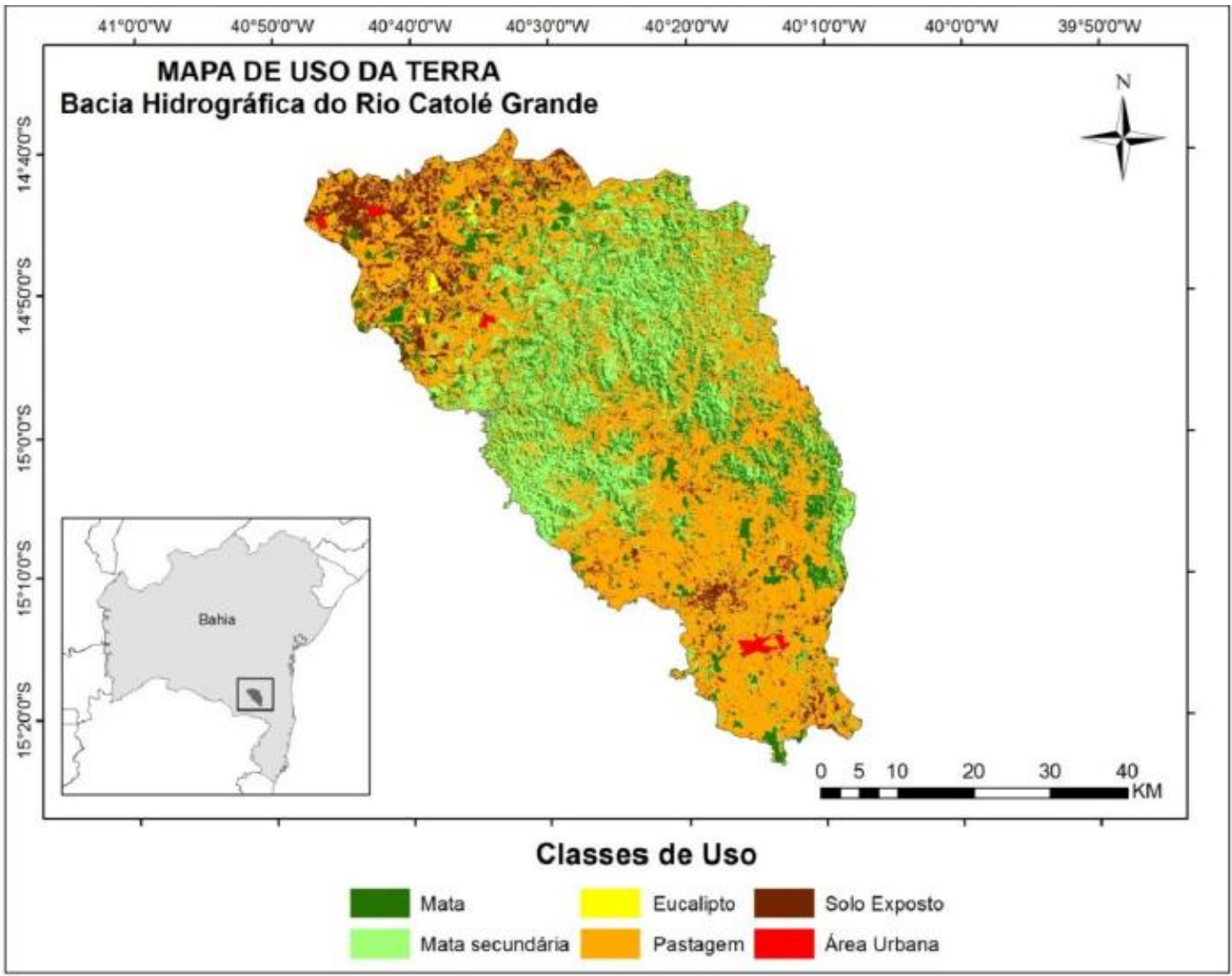

Figura 6 - Distribuição espacial das classes de uso da terra na bacia hidrográfica da bacia do rio Catolé Grande.

A inclusão do IQA na análise da fragilidade ambiental mostrou ter relevância no aumento das áreas de menor fragilidade potencial e redução daquelas com média, alta e muito alta fragilidade potencial provavelmente devido às condições encontradas de qualidade da água (boa e ótima) nos locais avaliados, sendo que os melhores índices foram encontrados no alto curso da bacia.

\section{Conclusões}

A integração das diversas informações ambientais utilizadas neste trabalho permitiu caracterizar o meio natural da bacia hidrográfica do rio Catolé Grande e avaliar as fragilidades potencial e ambiental.

A inclusão de fatores referentes aos recursos hídricos na análise da fragilidade potencial e ambiental possibilitou a obtenção de uma maior quantidade de informações importantes para a gestão e desenvolvimento sustentável da região.

Os aspectos referentes à vulnerabilidade dos recursos hídricos superficiais contribuíram para identificação de áreas com alta vulnerabilidade especialmente para a fragilidade potencial.

A inclusão do IQA mostrou-se relevante no aumento de áreas com baixa fragilidade ambiental. 


\section{Referências}

APHA - AWWA- WPCF. 1995. Standard methods for the examination of water and wastewater. 19th Edition. Wasghington D.C. American Public Health Association.

CETESB. 2004. Companhia de Tecnologia de Saneamento Ambiental. Águas. Rios e Reservatórios. Publicações/ Relatórios. Relatório de Qualidade das Águas Interiores do Estado de São Paulo. CETESB. Disponível em: < http://www.cetesb.sp.gov.br/Agua/rios/publicações.asp > Acesso em: 4 de set. 2011.

CPRM - Companhia de Pesquisa de Recursos Minerais. Relatório. 2010.

Crepani, E.; Medeiros, J. S.; Hernandez Filho, P.; Florenzano, T. G.; Duarte, V.; Barbosa, C. C. F. 2001. Sensoriamento remoto e geoprocessamento aplicado ao zoneamento ecológico-econômico e ao ordenamento territorial. INPE.

De Biasi, M. 1992. A carta clinográfica: os modelos de representação e sua confecção. Revista do Departamento de Geografia, v.6.

Emmanouloudis, D. A.; Christou, O. P.; Filippidis, E. I. 2003. Quantitative estimation of degradation in the Aliakmon River basin using GIS. Erosion Prediction in Ungauged Basins: Integrating Methods and Techniques. Proceedings of Symposium HS01. IAHS.
Harum, T.; Saccon, P.; Rego, N. A. C.; Paula, F. C. F.; Santos, J. W. B. 2008. Modelos de vulnerabilidade hidrológica para a bacia hidrográfica do rio Cachoeira (Bahia) utilizando sistemas de informações geográficas. Gaia Scientia, v. 1.

Kawakubo, F. S.; Morato, R. G.; Campos, K. C.; Luchiari, A.; Ross, J. L. S. 2005. Caracterização empírica da fragilidade ambiental utilizando geoprocessamento. In: Anais XII Simpósio Brasileiro de Sensoriamento Remoto, Goiânia, INPE.

Oliveira, J. T.; Moreau, A. N. S. S.; Menezes, A. A.; Paiva, A. Q.; Messias, T. 2007. Modificações ambientais e sócio-econômicas decorrentes do desenvolvimento da cafeicultura em Barra do Choça, Bahia. Bahia Agrícola,

Ross, J. L. S. 1994. Análises empíricas da fragilidade dos ambientes naturais e antropizados. Revista do Departamento de Geografia, USP.

SPÖRL, C. 2001. Análise da Fragilidade Ambiental Relevo - Solo com Aplicação de Três Modelos Alternativos nas Bacias dos Rio Jaguari-Mirim, Ribeirão do Quartel e Ribeirão da Prata. Dissertação Mestrado (Geografia Física) Universidade de São Paulo, São Paulo $-\mathrm{SP}$.

TOPODATA. 2009. Banco de Dados Geomorfométricos do Brasil.

Wischmeier, W. H.; Smith, D. D. 1978. Predicting rainfall erosion losses: a guide to conservation planning. Washington, DC: USDA. 